\title{
Ensaio da época de plantio de estacas de marmeleiro
}

\author{
J. SOUBIHE SOBRINHO \\ Instituto Agronômico \\ Sub-divisão de Horticultura \\ Campinas
}

e

HEITOR W. STUDART MONTENEGRO

Escola Superior de Agricultura "Luiz de Queiroz"

Universidade de São Paulo

Secção Técnica de "Horticultura"

Piracicaba

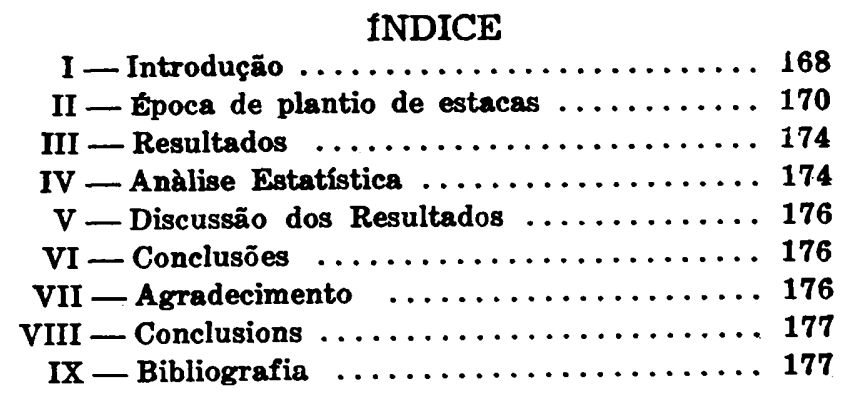




\section{INTRODUÇAOO}

O marmeleiro é originário da Pérsia. Cresce espontaneamente nas regiōes meridionais da França, Itália e nos bosques do Cáucaso. Acha-se em estado selvagem na ilha de Creta. E' cultivado desde o tempo mais remoto. Os romanos dedicavam seu fruto a Venus e era oferecido como símbolo da Felicidade, do Amor e da Fecundidade. Plinio e Virgilio fizeram elogios a êsse fruto.

O marmeleiro pertence à família das Rosáceas. Existem três espécies : - Cydonia vulgaris, Cydonia sinensis e Cydonia japônica. Estas duas últimas, são cultivadas mais para fins ornamentais. A primeira, Cydonia vulgaris, é a que deu ori'gem a tôdas as variedades existentes atualmente entre nós (7).

A cultura do marmeleiro não alcançou, nos Estados Unidos a importância econômica de grande parte dos outros frutos.

Embora o preço do marmelo seja muitas vezes, bastante elevado, não se deve concluir com êsse fato que a sua cultura seja suficientemente remuneradora. Isso se explica, porque as produções são frequentemente pequenas; muitas são as moléstias e pragas e o seu contrôle nem sempre fácil. Além disso, o uso do fruto é relativamente restrito, limitando-se a fabricação de geléa, marmelada, conservas e alguns outros produtos.

Em consequência da pequena importância econômica dessa cultura nos Estados Unidos, poucos têm sido os trabalhos experimentais realizados nesse grande país (3).

No Brasil, especialmente nos Estados de Minas Gerais e S. Paulo, a produção de marmelo, fruto muito apreciado pelo nosso povo já teve sua importância econômica.

$O$ engenheiro agrônomo Felisberto de Camargo (1), atualmente Diretor do Instituto Agronômico do Norte no Estado do Pará, no seu folheto sôbre a cultura do marmeleiro, diz: "Uns vinte anos atrás, em qualquer mercado do interior, o marmelo era a fruta comum dos meses de Janeiro e Fevereiro. Vinha, então a época das marmeladas em caixotes, em forma de xadrez, em lata e em forma de variadas fantasias, inclusive o clássico peixe.

Além da abundância que havia nas barracas do mercado, - marmelo era ainda vendido pelas carrocinhas ambulantes, que levavam também o tão apreciado fruto à porta da freguesia". 
O engenheiro agrônomo Drumond Gonçalves, Chefe da Secção de Fitopatologia do Instituto Biológico, na sua palestra levada a efeito em 1947 (2), na Bibliotéca Municipal de São Paulo, disse entre outras coisas o seguinte: "Baseando-se no Tratado Descritivo do Brasil em 1587, de Gabriel Soares de Souza, nas famosas cartas de Anchieta, de Manoel da Nóbrega, de Fernão Cardim e em muitas outras fontes históricas, Afonso de Taunay, o abalisado historiador e atualmente diretor do nosso Museu Paulista, publicava, em 1920, o seu documentado trabalho "São Paulo nos primeiros anos", livrinho valioso que deveria figurar na bibliotéca de todos os paulistas.

Nesse trabalho, que me parece reunir a melhor e mais completa documentação sôbre as primeiras culturas dessa árvore frutífera em terra paulista, encontramos um bom número de citações que bem mostram a grande importância que tinha, então o marmeleiro, para a economia de São Paulo.

Reportando-se, ao que Gabriel Soares escrevia em 1587, diz Taunay :

"Notavam-se em tôrno de São Paulo, tôdas as frutas de espinho que em Hespanha havia, as quais a formiga não fazia nojo" "Fartíssimos pomares circundavam a vila piratininga, onde uvas, figos, romãs, maçãs e marmelo vinham abundantíssimos. Já em S. Paulo havia moradores que colhiam duas pipas de vinho por ano. Como fosse muito verde, porém, tornava-se preciso dar-lhe uma fervura para que não avinagrasse".

"Alguns olivais já estavam produzindo excelente azeite e os marmelos eram tantos que dêles se faziam conservas, havendo tanta marmelada que a levavam a vender por outras capitanias".

E, continuando a analisar a grande importância da cultura de marmeleiro naquela época, Taunay nos relata a necessidade que tiveram as câmaras piratininganas de legislar "sôbre o artigo capital do comércio do tempo", dizendo que havia, no ano da graça, de 1597, tipos de marmelada como há hoje tipos de café.

Fala, depois, da obrigação que tinham os fabricantes de adotarem caixas estandartizadas para acondicioná-las; caixas que deveriam receber as marcas individuais, convenientemente registradas, para que se ficasse sabendo quem apresentava um bom ou mau produto.

Refere-se, também, às grandes multas e outras penas impostas aos que, por meio de vergonhosas falsificações, prejudicavam o excelente renome angariado pela marmelada piratiningana em todo o Brasil e nas vizinhas terras de Castella. 
Enfim, concretiza Afonso de Taunay, a sua farta e valiosa documentação a respeito dêsse assunto, afirmando-nos que, por mais de um século, teve a conserva paulista a mais acreditada reputação".

Com tudo isto, não quer dizer que naquela época havia cultura de marmelo pròpriamente dita, mas o que de fato existia era o seguinte : - nas fazendas, chácaras e quintais, plantavam-se estacas de marmelo que brotavam, entouceiravam e anualmente se cobriam de frutos. Progressivamente, a plantação de marmelo começou a desaparecer devido à uma moléstia causada pelo fungo Entomosporium maculatum.

Felizmente hoje, essa moléstia é perfeitamente controlada por meio de pulverizações.

Quanto ao incremento da cultura do marmeleiro, os fruticultores estão encontrando dificuldade na obtenção de mudas, bem como em sua produção.

A compra de mudas não é econômica porquanto os viveiristas esıão pedindo preços elevadíssimos por muda, 13 a 15 cruzeiros. Ora, se fosse plantado um alqueire de terra, com 2.500 mudas adquiridas de viveiristas, teriam de desembolsar cêrca de 32.500 cruzeiros, tornando-se dêsse modo, anti-econômica a exploração comercial; além disso, nem sempre essas mudas apresentam garantias no que diz respeito às suas boas qualidades de origem.

Logo, o mais interessante e econômico será o fruticultor produzir as suas próprias mudas.

O maior obstáculo à multiplicação dessa rosácea, de acôrdo com o que temos observado e conforme inúmeras queixas dos fruticultores, consiste no enraizamento das estacas.

Confirmando essa dificuldade encontrada no enraizamento das estacas de marmelo, basta dizer que em uma plantação por nós realizada, com cêrca de 800 estacas, muito pouco satisfatório foi o resultado obtido.

Encontrâmo-nos, pois, diante de um problema de cuja rápida solução depende o futuro desenvolvimento da cultura do marmeleiro em São Paulo. (6)

\section{II - EPOCA DE PLANTIO DE ESTACAS}

A época de se proceder a estaquia das plantas lenhosas, como é o caso do marmeleiro, é desde fins de outono até princípios da primavera, quando os ramos atingiram o seu completo desenvolvimento e já, então, perderam suas folhas ou se encontram em estado de repouso. 
Existe, porém, dentro desta época, um momento mais propício para cada planta, de acôrdo com suas exigências.

Este foi o fito dêste trabalho, quando iniciamos em Junho de 1948 : determinar o momento próprio em que se deve proceder a estaquia do marmeleiro.

Quem está acostumado a lidar com esta planta, conhece o problema de sua multiplicação. Um pegamento de 30 a $50 \%$ é considerado ótimo porque o que se vê comumente no viveiro de marmeleiros é o pegamento de poucas mudas, entre 0 a $20 \%$. A estaquia de plantas lenhosas, como é o caso da videira, macieira, marmeleiro, é sempre feita nos fins de Julho, comêço de Agôsto. Entretanto, o que se observa nas estacas de marmeleiro, plantado nesta época, é que logo em seguida à plantação ela emite uma brotação e forma-se um bonito raminho, com algumas folhas. Isso se dá em quase $100 \%$ das estacas. Umm leigo, rejubilar-se-ia com isso; porém um conhecedor do assunto, saberia logo que dentro de pouco tempo, um a um os brotos ir-se-ão secando, sobrando uma pequena percentagem.

O que se dá com as estacas do marmeleiro é o seguinte : plantadas em Julho ou em Agôsto, elas, com o início da primavera encontram-se sob a ação de calor e luz que as faz brotar e de uma grande umidade, devido às regas continuadas, que as impedem de murchar. Essa brotação se dá às expensas de suas próprias reservas. Como o enraizamento se processa muito lentamente ao se esgotarem aquelas, os brotos perecem e com êles, as estacas. Quando iniciamos os estudos sôbre o assunto, ficou mais ou menos objetivado o seguinte: que a brotação das estacas se dava com muita rapidez, o que determinava a extinção de suas reservas, antes da formação das primeiras raizes. e que, prejulgamos nós, a plantação antecipada das estacas dando tempo a que o enraizamento se processasse antes da brotação, fosse a solução.

Resolvemos então traçar um plano abrangendo 6 épocas de plantação.
1a. -15 de junho
2a. -30 de junho
3a. - 15 de julho
4a. -30 de julho
5a. - 15 de agôsto
6a. - 30 de agôsto 
Os limites escolhidos, 15 de junho a 30 de agôsto, foram tomados levando-se em consideração que as estacas são provenientes de ramos podados de marmeleiros que estão em produção, e que a maior preocupação dos fruticultores é de podar bem, a altưra certa e na época propícia. Do produto da poda, posteriormente confeccionarão estacas de que necessitam. Mesmo os viveiristas que retiram para multiplicação, ramos das chamadas "plantas mães", procuram podar com acerto para não prejudicar as colheitas vindouras, outra fonte de rendas para êles. Achamos que antes de Junho a poda seria bastante antecipada, com perigo de uma brotação invernal e sua morte devido às geadas. Também uma poda em Setembro, não seria concebível, pois, quase sempre nesta época, os marmeleiros já se encontram em brotação.

Levando êstes pontos em consideração, adotamos aquelas épocas para nossa experiência.

O número total de estacas por época ou tratamento foi de 240 divididas em 4 repetições de 60 - distribuidas ao acaso (fig. 1).

Antes, naturalmente, preparamos o terreno, êste de mais ou menos 8 por $40 \mathrm{mts}$., foi arado, gradeado e adubado.

E' um lote de terra roxa do viveiro da Secção Técnica de "Horticultura" da Escola Superior de Agricultura "Luiz de Queiroz", da Universidade de São Paulo. Se bem que soubessemos os defeitos daquela terra para a estaquia de frutíferas, como o marmeleiro, especialmente no que se refere a sua compacidade, não nos foi possível a escolha de outro local, devido, à falta d'água e outros fatores.

A variedade usada na experiência foi a chamada Mato Dentro também conhecida como marmeleiro comum. A irrigação foi feita de dois em dois dias. 


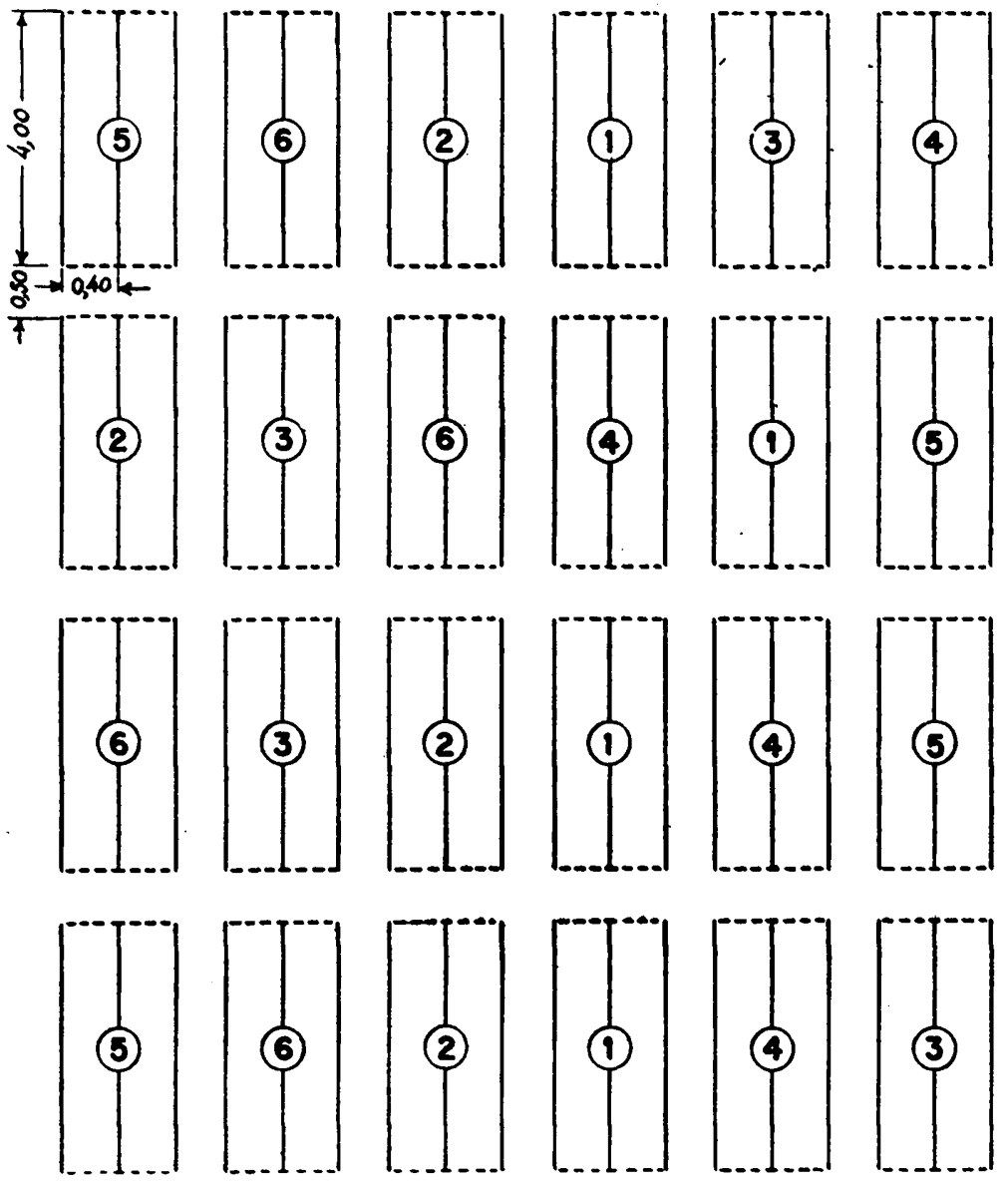

F1g. I - Blocos distribuldos ao acaso. 


\section{III - RESULTADOS}

No dia 22 de março de 1949, quando tôdas as estacas já demonstravam estar bem enraizadas, precedemos ao levantamento das mesmas, com os seguintes resultados :

\begin{tabular}{|c|c|c|c|c|}
\hline & Bloco 1 & Bloco 2 & Bloco 3 & Bloco 4 \\
\hline 1. época & 16 & 26 & 28 & $: 9$ \\
\hline 2. época & 4 & 10 & 9 & 10 \\
\hline 3. época & 21 & 10 & 4 & 17 \\
\hline 4. época & 6 & 1 & 3 & 3 \\
\hline $5^{a}$ época & 7 & 8 & 7 & 3 \\
\hline 6. época & 7 & 3 & 2 & 5 \\
\hline
\end{tabular}

IV - ANALISE ESTATISTICA

Feita a análise estatística, obtivemos os seguintes resultados:

\begin{tabular}{|c|c|c|c|c|c|c|}
\hline Blocos & $1 .^{\circ}$ & $2 .^{\circ}$ & 3. ${ }^{\circ}$ & $4 .^{\circ}$ & $\begin{array}{c}\text { Tratamento } \\
\text { Total }\end{array}$ & Médias \\
\hline 1." época & 16 & 26 & 28 & 29 & 99 & 24,75 \\
\hline 2." época & 4 & 10 & 9 & 10 & 33 & 8,25 \\
\hline 3. época & 21 & 10 & 4 & 17 & 52 & 13,00 \\
\hline 4. época & 6 & 1 & 3 & 3 & 13 & 3,25 \\
\hline 5. época & 7 & 8 & 7 & 3 & 25 & 6,25 \\
\hline 6. época & 7 & 3 & 2 & 5 & 17 & 4,25 \\
\hline Total & 61 & 58 & 53 & 67 & 239 & \\
\hline
\end{tabular}




\begin{tabular}{|c|c|c|c|}
\hline$\cdots$ & Variância & Hrro Standard & $\begin{array}{l}\text { Gráu de } \\
\text { liberdade }\end{array}$ \\
\hline Blocos & 5,71 & $\pm \quad 2,39$ & 3 \\
\hline Tratamentos & 257,84 & $\pm 16,06$ & 5 \\
\hline Resto & 21,77 & 4,74 & 15 \\
\hline
\end{tabular}

O $\vartheta$ teste para comparação do êrro de tratamentos com o êrro experimental nos dá :

$$
\vartheta=\frac{16,06}{4,74}=3,39 \quad \stackrel{(5 \%-1,70}{(1 \%-2,13} \text { significativo }
$$

Para a comparação do êrro de blocos com o êrro experimental o mesmo teste nos dá :

$$
\vartheta=\frac{2,39}{4,74}=0,50 \quad \stackrel{(5 \%}{(1 \%-0,47}-0,32^{\text {não significativo }}
$$

O resultado da experiência foi, portanto, significativo.

Vejamos então quais os tratamentos que se destacam. $O$ êrro de diferença entre duas médias de tratamentos dá :

$\sigma$ dif. $= \pm \sqrt{\frac{21,77 \times 2}{4}}= \pm \sqrt{\underline{10,88}}= \pm 3,30$

As médias obtidas foram

$\begin{array}{lllr}\text { 1a. - época } & \overline{\mathrm{V} 1} & =24,25 \\ \text { 2a. - época } & \overline{\mathrm{V} 2} & = & 8,25 \\ \text { 3a. - época } & \overline{\mathrm{V} 3} & = & 13,00 \\ \text { 4a. - época } & \mathrm{V} 4 & = & 3,25 \\ \text { 5a. - época } & \mathrm{V} 5 & = & 6,25 \\ \text { 6a. - época } & \mathrm{V} 6 & = & 4,25\end{array}$


Verifica-se pelo t-teste que a 1a. época é significativamente superior a tôdas as outras. A 3a. época apresenta diferença significativa em relação a $4 a$., duvidosa em relação a 6a. e não significativa em relação às demais. As outras tôdas se equivalem.

\section{V - DISCUSSAO DOS RESULTADOS}

Pela análise estatística, vemos que a estaquia feita mais cedo, sortiu melhor efeito. A primeira época - 15 de junho foi de fato bem superior às outras. Esse resultado deu margem a que levantássemos a seguinte premissa, se em uma época ainda mais cedo, o pegamento seria maior. Neste caso, viriam à baila aquelas considerações que fizemos, ao escolhermos apenas 6 épocas para a experiência. Porém, achamos que sòmente uma nova experiência, com mais algumas épocas antecipadas, e uma comparação entre a elevação da percentagem de pegamento e o prejuizo ou não acarretado pela antecipação da poda, nos daria uma resposta satisfatória àquele ponto. E' o que pretendemos realizar neste ano.

Julgamos que em terreno mais próprio àquela cultura, a percentagem de enraizamento seja maior.

\section{VI - CONCLUSÕES}

1a.) A primeira época - 15 de junho - determinou um maior pegamento nas estacas de marmeleiro.

2a.) Uma nova experiência será efetuada êste ano, porque talvez a estaquia feita em maio ou princípio de junho, cause um enraizamento mais cedo, e, dêste modo haja um maior pegamento.

\section{VII - AGRADECIMENTO}

Deixamos aqui consignados os nossos agradecimentos ao Dr. Frederico Pimentel Gomes, por sua assistência prestada na análise estatística dos resultados, bem como aos Engs. Agrô- 
nomos R. Drumond Gonçalves e Orestes Falanghe, pelo fornecimento do material utilizado nesta experiência e ao Prof. Dr. Phelippe W. Cabral de Vasconcellos, pelas facilidades concedidas e conselhos emitidos sôbre o presente trabalho.

\section{VIII - SUMMARY AND CONCLUSIONS}

In this article the authors make a study to find the best period for the planting of Quince-tree cuttings. Experiments were made during 6 periods. The cuttings were planted in "terra roxa".

The variety used was "Mato Dentro".

\section{Conclusions,.}

I - The first period - June 15 - resulted in the rooting of a larger number of Quince-tree cuttings.

II - There will be a new experiment made this year because there might be a larger number of cuttings that would grow due to a possible earlier rooting if planted in May or the first of June.

\section{IX - BIBLIOGRAFIA}

Trabalhos citados e consultados:

10. - CAMARGO, F. C. e R. DRUMOND GONÇALVES - A cultura do marmeleiro - O combate a Entomosporiose - Departam. Prod. Vegetal - Circular n. 13 - pág. 1 -2a. edição. 1943.

20. - GONÇALVES, R. DRUMOND - Novos passos para a restauração da cultura do marmeleiro em São Paulo Relatório anual do Instituto de Botânica do Estado de São Paulo - pág. 77-79. 1944.

3o. - GOUD, H. P. Quince Growing - Leaflet n. 158 - U. S. - Departament of Agriculture - Washington, D. C. 1938. 
40. - GRUMBERG, I. P. - El arte de criar e injertar frutales - pág. 26-28 - 3a. edição - Buenos Aires. 1940.

5o. - MOTTET, S. - Guide élémentaire de multiplication et d'education des vetaux. Deux ieme édition. Paris, Librairie Octave Doin. 1923.

6o. - SOUBIHE SOBR., J. - Em relatorio da Seç̧ão de Vitucultura e Frutas de Clima Temperado, do Instituto Agronômico do Estado de S. Paulo - (Campinas). 19461947. (Não publicados).

7o. - TAMARO, DOMENICO - Tratado de fruticultura Vol. Secondo, pág. 671-681. Editore Ulrico Hoepli-Milano. 1925.

80. - VIDAL, JOSÉ J. - Multiplicacion de los frutales - Editorial Dudamericana - Buenos Aires. 1941.

9o. - VASCONCELLOS, PHELIPPE WESTIN CABRAL. Apontamentos de aulas de Horticultura. 1946 - (Não publicado). 